\title{
Using a lecturer's personal Web site to enhance the social interchange among students in an academic course
}

\author{
David Passig \\ School of Education, Bar-Ilan University, 52900 Ramat-Gan, Israel. \\ passig@mail.biu.ac.il
}

Key words: Collaborative Learning, Higher Education, ICT, Social Issues, Virtual University

Abstract: Developments in web-based communication technology have opened up new ways for students at a distance to communicate with their teachers and with each other. The literature covers three types of web-based interactions: learnercontent interaction, learner-instructor interaction, and learner-learner interaction. However, the purpose of this study was to examine a newer aspect in these relationships. The aim was to investigate the social impact of a lecturer's personal web site on the personal interchange with his students. The participants were sixty-three students undertaking one of the author's graduate courses at Bar-Ilan University. They were given learning assignments, which required social interaction to complete, using a variety of Peer-to-Peer technologies. The results show that most of the students found the lecturer's personal web site an efficient P2P (Peer-to-Peer) tool that enhanced social interchange outside the walls of the class. Over $85 \%$ of the students strongly recommended that personal aspects delivered only on a personal web site should be added into academic courses.

\section{INTRODUCTION}

Developments in electronic communication have opened up new ways for students to communicate with their teacher and with each other at a

The original version of this chapter was revised: The copyright line was incorrect. This has been corrected. The Erratum to this chapter is available at DOI: 10.1007/978-0-387-35663-1_34 
distance. There are three main types of interactions detailed in the literature (Moore 1989; Tribe 1994):

- Learner-content interaction. This process of intellectually interacting with content results in changes in the learner's understanding, that is, learning.

- Learner-instructor interaction. The instructor can stimulate or maintain the student's interest, organise the learning experience, present information, assess and provide information on progress, and provide counsel, support and encouragement. On-line tutoring ranges from comments on the return of an assignment, through posing questions to guide reading and research, to leading discussions on a topic.

- Learner-learner interaction. Interaction between one learner and other learners is the way students consolidate their ideas, test hypotheses, and confirm opinions and attitudes. Research into peer interactive learning demonstrates that students who work cooperatively achieve superior results to those working in individualistic or competitive ways. In particular, the practice of students giving and receiving advice and assistance from one another shows a positive relationship with achievement.

To achieve these kinds of learning a variety of learning strategies can be employed. Kibby (1999) lists a number of these, including:

- Panel discussion - a group of 'experts' initiate a discussion on a set topic, students join in at any point, and the experts play a diminishing role as the discussion progresses;

- Brainstorming - setting forth of ideas without evaluation;

- Problem solving exercise - small groups work out a solution to a problem;

- Teamwork games - adapted from small group 'bonding' exercises;

- Role playing - such as MUDs and MOOs that are forums based on role playing;

- Simulation - MOOs can also provide settings for simulations;

- Co-tutoring - students are assigned topics which they then 'teach' to another student;

- Case analysis - independent study of a case or representative example followed by group analysis;

- Collaborative writing - group writing, or individual writing followed by mutual critiquing;

- Expert in electronic 'residence' - an expert is available to make presentations, be interviewed and lead discussions;

- Interview - questions can be asked of the instructor, designated student or other resource person, followed by discussion; 
- Debate - the pros and cons of a particular issue are argued by a team, and then the audience allocates their support for one opinion;

- Student reports - individuals post a report on which others then comment;

- Discussion of set reading - threaded discussions with comments on each required reading.

A range of studies has been conducted to test the effectiveness of these strategies on social aspects of the learning processes. Powers and Mitchell (1997) examined one graduate course which was offered entirely over the Internet. From the analysis of student performance and perceptions in this particular class, it is apparent that even as virtual classrooms become more prolific, the classroom community of learners can continue to flourish.

Another study investigated uses and gratifications of the web and it's social impact (Kaye 1998). The study identified six web use motivations entertainment, social interaction, passing of time, escape, information, and web site preference.

A study of the attitudes of 29 graduate students enrolled in their first web-based class indicated a high degree of student-to-teacher and student-tostudent interaction as well as accompanying high levels of satisfaction (Westbrook 1999).

One study examined a graduate distance course for elementary-school teachers using a "class web page" to increase teacher-student and peer interaction. Periodic student surveys during the course showed the dramatic impact of the class page on student interaction behaviours, technology use and literacy, and attitudes toward technology (Thompson et al 1998).

Our study addressed a different aspect of social interchange. There was no course designed on the net. Instead the study investigated the effects that a lecturer's personal web site can have on the relationships and online social community that can emerge from and follows a conventional academic course.

More and more instructors are building personal web sites and using them as teaching tools and as vehicles to achieving a variety of teaching purposes. Our study investigated the social role such a personal web site can exercise in enhancing the social links among the instructor's students following the usual social interchange which takes place in the classroom on an academic course.

To the best of our knowledge no other research study has been conducted into the influence an instructor's personal web site has had on the students' social interactions outside the walls of the classroom. 


\section{THE BAR-ILAN STUDY}

\subsection{Participants}

The participants were 63 students takin one of the author's graduate courses at the University. During the acad mic school year, the students were given assignments via the instructor' site (http://www.passig.com) using a variety of Peer-To-Peer technologic. At the end of the academic year, the students were asked to answer a qu stionnaire in order to examine the influence of the web site on their extra cu icular social interactions.

\section{$2.2 \quad$ P2P Technologies}

We used different technologies to facilitc e a variety of interchange and collaboration among the students. The three lain tools we used extensively were BrowseUp, eQuill and Groove.

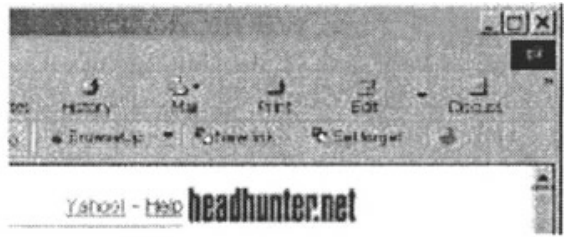

Figure 1. BrowseUp toolbar

BrowseUp (www.browseup.com) has at its core technology that enables users to create virtual links from existing online documents (Figure 1). Although these virtual links are inline links, they really reside on a link server (and not within the page), and the original document is not changed. These virtual links can point from both pictures and text within the page to associatively connected information like other URLs, the users local files (which are automatically published), and to new pages written on the fly by the user. Other users can view the virtual links while they access the URL from where the links point.

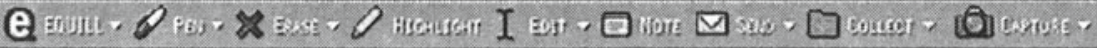

Figure 2. eQuill toolbar

eQuill (http://www.equill.com) was a nice tool (Figure 2). It streamlines and automates the manual process of designing, reviewing, approving, and 
maintaining Web sites. eQuill Markup Client allows you to mark up, highlight, edit, and post notes to Web pages or documents directly through your browser.

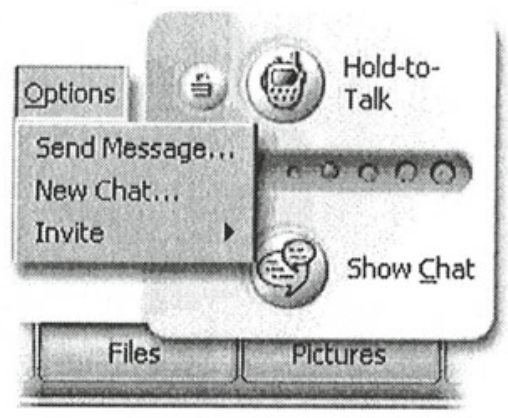

Figure 3. Some features of Groove

Groove was a collaboration tool we found to be very effective. It enables a small group of students to talk, work, play, and share things with teammates inside shared spaces over the web (Figure 3). Groove lets you create interactive shared spaces as required, inviting the members you want and adding tools that match the task at hand. Groove complements existing productivity resources - including Microsoft Office and e-mail - with tools for communicating, sharing information and working together. You can see an example of a shared space at:

http://www.groove.net/products/individual/sharedspace.html.

Groove supports both online and offline use, letting the group work with each other in real-time or disconnected whenever they like, providing ongoing meeting and project management. The software works across network firewalls and other technical boundaries providing dispersed and mobile teams with on-demand, private networks.

Groove sits securely on the users PC, letting them control how, when and with whom they interact. No set-up configuration or server administration is required. After installing Groove, team-mates can hold meetings, edit presentations and write new ideas.

\subsection{Forums and Students' list}

We have provided a variety of topic-based forums to discuss issues raised during the class sessions. We have also posted a list of students with contact information. Only one student didn't want her name and contact information to be posted to the public through the site. The idea behind the students' list 
and the forums was to provide another means whereby social interaction can be enhanced.

\section{EVALUATION}

We couldn't find an appropriate questionnaire to evaluate the social interaction among students while using a personal web site. At the end of the academic year we asked the students to suggest a list of questions that can be circulated among the participants to evaluate the social impact of the lecturer's site on their social interchange outside the walls of the classroom. While this was not a viable validation technique, we found it suitable as an initial attempt to develop such a questionnaire. Through a collaborative effort we came up with a list of 14 statements. Participants were asked to evaluate the statements using a five-point scale (Table 1).

Table 1. List of statements

\begin{tabular}{|c|c|c|c|}
\hline Statement & $\begin{array}{l}\text { Strongly } \\
\text { disagree }(1,2)\end{array}$ & Undecided & $\begin{array}{l}\text { Strongly } \\
\text { agree }(4,5)\end{array}$ \\
\hline $\begin{array}{l}\text { Site is a good vehicle to better socially } \\
\text { connect the lecturer with the student. }\end{array}$ & - & - & 78 \\
\hline $\begin{array}{l}\text { Site a good vehicle to better socially } \\
\text { connect the student with the lecturer. }\end{array}$ & - & - & 76 \\
\hline $\begin{array}{l}\text { The Forum is a good vehicle to get updated } \\
\text { on the learning assignments. }\end{array}$ & 52 & 12 & 36 \\
\hline I am an active participant in the Forum. & 64 & 10 & 26 \\
\hline $\begin{array}{l}\text { The Forum helped me communicate with } \\
\text { other students. }\end{array}$ & 64 & 10 & 26 \\
\hline $\begin{array}{l}\text { I received suitable answers to my questions } \\
\text { through the Forum. }\end{array}$ & 67 & 13 & 20 \\
\hline $\begin{array}{l}\text { The Forum can provide a suitable platform } \\
\text { for open social interchange. }\end{array}$ & 29 & 10 & 61 \\
\hline $\begin{array}{l}\text { I use the students' list to locate contact } \\
\text { information and e-mail addresses. }\end{array}$ & 47 & 11 & 42 \\
\hline $\begin{array}{l}\text { The P2P tools were used effectively } \\
\text { through the lecturer's site. }\end{array}$ & 35 & 35 & 30 \\
\hline $\begin{array}{l}\text { The site is a good environment to serve the } \\
\text { P2P tools and accommodate social } \\
\text { interchange between students \& lecturer. }\end{array}$ & 30 & 16 & 54 \\
\hline $\begin{array}{l}\text { The site is a good environment to serve the } \\
\text { P2P tools and accommodate social } \\
\text { interchange between the students. }\end{array}$ & 20 & 25 & 55 \\
\hline $\begin{array}{l}\text { The site with } \mathrm{P} 2 \mathrm{P} \text { tools adds additional } \\
\text { social aspects to the learning process. }\end{array}$ & 23 & 14 & 63 \\
\hline $\begin{array}{l}\text { It's important to add P2P dimensions to } \\
\text { academic courses. }\end{array}$ & 17 & 9 & 74 \\
\hline The P2P experience was enjoyable. & 12 & 16 & 72 \\
\hline
\end{tabular}




\section{DISCUSSION}

In recent years there has been a growing pressure on academic and nonacademic lecturers to develop and post personal web sites. The motive behind this pressure appears to be the promotion of the lecturer's professional image and the academic profile of their institutions. Most of the sites being developed aim to deliver personal information as well as a variety of teaching materials, assignments and complementary contents relevant to the interest and research scope of the lecturers. This trend is taking off among the vast majority of lecturers - worldwide and across disciplines. In just a few years it is reasonable to speculate that most academic lecturers will have a personal visibility on the web either through private servers or their institution's infrastructures. Personal web sites will probably take on the role of teaching tools for a variety of educational purposes. At this early stage it is important to develop new teaching strategies to better exploit the potential of personal web sites as teaching tools.

The underlying assumption of this study was that personal web sites could provide more than is normally thought possible today. Our assumption was that this educational tool is underestimated but it offers the opportunity to achieve educational aims that cannot be achieved in the conventional 'bricks and mortar' teaching environment. Indeed, the aim of this study was to investigate the role of a personal web site in providing new opportunities to further extend social interchange either around issues being discussed in classroom settings or around personal interchange.

The results clearly indicate that a personal web site with a variety of appropriate $\mathrm{P} 2 \mathrm{P}$ technologies can further enhance the social extra-curricular interchange among students and lecturer as well as among students themselves.

One striking result of this study indicates that the students didn't see the Forums to be suitable for their social interchange. Most of the studies (Burstall 2000; Corbett and Eikum 2000) that looked at the role of Forums in the learning process did find some degree of learning interchange was achieved through Forums. However, it seems it did not provide social interchange, at least as it has been demonstrated in this study. One reason may be that of the nature of the Forum as a public venue, which was not the preferred option for conducting social and more personal and intimate interchange. Another reason may be that of the nature of the technology when set side by side with much more powerful P2P technologies such as Groove and BrowseUp.

Tomorrow's "brick and click" approach could provide new opportunities and challenges to teaching and learning. It would represent a convergence of old and new teaching techniques. The Internet is taking the basic bricks and 
mortar learning process - a physical location - and is moving it to the click of the Internet. This Internet presence has to be linked with the front end as well as the back end of Pedagogy. This study indicates that we need to reform our expectations of the new click and brick tools. On the one hand we need to lower our expectations from tools such as Forums and on the other hand raise our expectations in regard to $\mathrm{P} 2 \mathrm{P}$ tools in the socialising process which accompanies learning.

\section{REFERENCES}

Burstall, J. (2000) Learning Communities for Social Change in Forums on the Web. Australian Journal of Adult Learning, Volume 40 (2) pp:33-52.

Corbett, D. R. and Eikum, D. (2000) Social Impact of Distance Learning in Higher Education on Health, Physical Education, and Recreation Students. Jones Institute for Educational Excellence, the Teachers College, Emporia State University, Emporia, KS 66801-5087. ED449160

Kaye, B. K. (1998) Uses and gratifications of the World Wide Web: From couch potato to Web potato. New Jersey Journal of Communication. 6 (1) pp. 21-40.

Kibby, M. (1999) Teaching and learning on-line.

[http://www.newcastle.edu.au/department/so/interact.htm]

Moore, M. G. (1989) Editorial: three types of interaction. The American Journal of Distance Education. Volume 3 (2) Editorial.

Powers, S. M. and Mitchell, J. (1997) Student perceptions and performance in a virtual classroom environment. Proceedings - Annual Meeting of the American Educational Research Association, Chicago, Illinois.

Thompson, J.C., Malm, L.D., Malone, B.G., Nay, F.W., Oliver, B.E. and Saunders, N.G. (1998) Enhancing Classroom Interaction in Distance Education Utilizing the World Wide Web. Mid-Western Educational Researcher. 11 (4) pp. 3-7.

Tribe, D. (1994) An overview from higher education. In Using Group Based Learning in Higher Education London, L. Thorley and R. Gregory (eds.), Kogan. pp. 25-30.

Westbrook, T. S. (1999) Changes in student attitudes toward graduate instruction via Webbased delivery. Journal of Continuing Higher Education. Volume 47(2) pp. 32-38. 